\title{
Clinical Study \\ Serum Lipid Profile of Newly Diagnosed Hypertensive Patients in Nnewi, South-East Nigeria
}

\author{
Charles U. Osuji, ${ }^{1}$ Emeka G. Omejua, ${ }^{2}$ Emmanuel I. Onwubuya, ${ }^{1}$ and Gladys I. Ahaneku1 \\ ${ }^{1}$ Department of Medicine, Nnamdi Azikiwe University Teaching Hospital, PMB 5025, Nnewi 435101, Anambra State, Nigeria \\ ${ }^{2}$ Department of Medicine, Federal Medical Centre, P.O. Box 1010, Owerri 460281, Imo State, Nigeria
}

Correspondence should be addressed to Charles U. Osuji, ukacharly@yahoo.com

Received 14 August 2012; Revised 8 November 2012; Accepted 9 November 2012

Academic Editor: B. Waeber

Copyright (C) 2012 Charles U. Osuji et al. This is an open access article distributed under the Creative Commons Attribution License, which permits unrestricted use, distribution, and reproduction in any medium, provided the original work is properly cited.

\begin{abstract}
Abnormalities in serum lipid and lipoprotein levels are recognized major modifiable cardiovascular disease and essential hypertension risk factors. The objective of this study was to examine the serum lipid patterns of newly diagnosed hypertensive patients attending a tertiary healthcare centre in South East Nigeria. Methods. Two hundred and fifty newly diagnosed adult hypertensive patients and an equal number of age- and sex-matched controls without hypertension were consecutively recruited from the Medical and General Outpatient Clinics of Nnamdi Azikiwe University Teaching Hospital, Nnewi. Result. 126 males and 124 females were in each of the two groups. Mean age was comparable in both groups. Hypertensives had significantly higher mean systolic blood pressure, diastolic blood pressure, body mass index, waist circumference, waist-hip ratio, and fasting blood sugar than the controls. The mean TC, TG, and LDL-C were significantly higher among the hypertensives. The mean HDL-C was comparable; $P=0.8$. Among the hypertensive subjects, there was statistically significant positive correlation between BMI and TC; LDL-C and TG; WC and TG; FBS and TC; LDL-C and TG. HDL-C showed a statistically significant inverse correlation with WHR in hypertensives. Conclusion. This study showed that lipid abnormalities are highly prevalent among newly diagnosed hypertensives in South-East Nigeria.
\end{abstract}

\section{Introduction}

Abnormalities in serum lipid and lipoprotein levels (dyslipidemia) are recognized as major modifiable cardiovascular disease (CVD) risk factors [1] and have been identified as independent risk factors for essential hypertension giving rise to the term dyslipidemic hypertension $[2,3]$.

Dyslipidemia is more common in untreated hypertensives than normotensives, and lipid levels increase as BP increases $[4,5]$. Though no specific pattern of dyslipidemia has been consistently reported among hypertensive individuals, many studies have shown that total cholesterol (TC), triglycerides (TG), and virtually all fractions of lipoproteins tend to be more frequently abnormal among hypertensive patients than in the general population. In general, black Africans have been reported to have lower serum total cholesterol and higher high-density lipoprotein cholesterol (HDL-C) than whites and other blacks in industrialized countries; however, as in Westernized countries, age, sex, socioeconomic status, and diet also significantly affect lipid levels in healthy Africans [6-9].

In Nigeria although the incidence of coronary artery disease and atherosclerosis is still low, it is rising as atherosclerotic lesions of the aorta, coronary, and cerebral arteries are being reported $[10,11]$. Hypertension is a powerful risk factor for cardiovascular disease and it remains one of the biggest health and economic issues facing the world $[12,13]$ and in Nigeria the prevalence of hypertension is known to have varied from $11 \%$ to $45 \%$ [14-16].

Hypertension is known to be associated with alterations in lipid metabolism which gives rise to abnormalities in serum lipid and lipoprotein levels. It has also been documented that presence of hyperlipidaemia substantially worsens the prognosis in hypertensive patients [17].

The frequent clustering of hypertension, lipid abnormalities, and other metabolic abnormalities, in an individual has 
been clearly demonstrated to be synergistic in accelerating atherosclerosis and development of CVD [18]. With the current trend of increasing incidence and prevalence of hypertension, CVD, and other noncommunicable diseases coupled with the persistence of high rates of communicable diseases in most developing countries, these countries have been said to be experiencing a "double burden of disease."

The objective of this study was to examine the serum lipid patterns of newly diagnosed hypertensive patients attending a tertiary healthcare centre in South East Nigeria.

\section{Materials and Methods}

Two hundred and fifty newly diagnosed adult hypertensive patients and an equal number of age- and sexmatched controls without hypertension were consecutively recruited from the Medical and General Out-patient Clinics of Nnamdi Azikiwe University Teaching Hospital, Nnewi, were studied. It was a hospital-based cross-sectional study. Relevant sociodemographic data and history were obtained, physical examination was carried out, and anthropometric measurements were taken during subjects' first visits to the clinics. Blood pressure was taken on the left arm after 5 minutes' relaxation, in a sitting position, using a standard mercury sphygmomanometer with appropriate cuff size; systolic (SBP) and diastolic (DBP) blood pressures corresponded to Korotkoff sounds 1 and $\mathrm{V}$, respectively. The average of three readings, taken at first visit, was used for further analysis. Height and body weight were measured with participants standing without shoes and heavy outer garments. Body mass index (BMI) was calculated as weight, divided by height squared $\left(\mathrm{kg} / \mathrm{m}^{2}\right)$. Hip and waist were measured to the nearest $1 \mathrm{~cm}$ and waist-to-hip ratio (WHR) was calculated as waist circumference divided by hip circumference. Fasting blood glucose and fasting serum lipid profile were determined using a 12-mL sample of blood obtained from an antecubital vein following an overnight (i.e., about 9-12-hour) fast. Serum total cholesterol (TC), high density lipoprotein cholesterol (HDL-C), and triglycerides (TG) were determined enzymatically, while low density lipoprotein cholesterol (LDL-C) was calculated using the Friedwald formula.

Hypertension was diagnosed based on the JNC-7 criteria [19]. An informed signed consent was needed to be recruited into the study and those who refused were not recruited into the study. Hypertensive subjects who were already on antihypertensive medications and those with known or suspected secondary hypertension were not recruited. Other exclusion criteria were: prior diagnosis of diabetes mellitus, pregnancy, current or recent intake of drugs such as statins, beta blockers, and so forth that affect lipid metabolism. Serum total cholesterol (TC), low-density lipoprotein cholesterol (LDL-C), high density lipoprotein cholesterol (HDLC), and triglyceride (TG) levels were classified on the basis of the Third Report of the Expert Panel on Detection, Evaluation, and Treatment of High Blood Cholesterol in Adults (ATP III) [18]. Elevated TC was defined as having TC levels of $>5.17 \mathrm{mmol} / \mathrm{L}(200 \mathrm{mg} / \mathrm{dL})$. Low HDL-C was defined as having HDL-C levels $<1.03 \mathrm{mmol} / \mathrm{L}(<40 \mathrm{mg} / \mathrm{dL})$ elevated LDLC was defined as having LDL-C levels of $>3.38 \mathrm{mmol} / \mathrm{L} \quad(>130 \mathrm{mg} / \mathrm{dL})$. Elevated TG was defined as having triglyceride levels of $>1.69 \mathrm{mmol} / \mathrm{L}(>150 \mathrm{mg} / \mathrm{dL})$.

Ethical clearance was obtained from the Nnamdi Azikiwe University Teaching Hospital Ethical Committee (NAUTHEC).

\section{Statistical Analysis}

Data was analyzed using the Statistical Package for Social Sciences (SPSS) version 16.0 software (SPSS Inc., Chicago, IL, USA). Simple descriptive statistics was used to present the demographic characteristics of the study participants. Continuous variables were presented as mean \pm standard deviation and were compared using the student $t$-tests while Chi-square $\left(\chi^{2}\right)$ tests were used to compare categorical variables. Other associations were evaluated with Spearman's correlation coefficient as well as multiple linear regression analysis. A $P$ value of $<0.05$ was considered statistically significant.

\section{Results}

The clinical and biochemical characteristics of the study participants are shown in Table 1. The hypertensive subjects and the controls were matched for age and sex. Among each of the 2 groups, there were 126 males and 124 females $(1.02: 1)$. The mean age of the subjects $(58.5 \pm 12.4$ years $)$ was comparable to that of the controls $(57.8 \pm 12.5$ years $)$. The hypertensive subjects had significantly higher mean systolic blood pressure (SBP), diastolic blood pressure (DBP), body mass index (BMI), waist circumference (WC), waist-hip ratio (WHR), and fasting blood sugar (FBS) than the controls. The mean TC $(4.83 \pm 0.95$ versus $4.15 \pm 0.57$, $t=-9.70, P<0.001)$, TG $(1.23 \pm 0.32$ versus $1.10 \pm 0.24$, $t=-5.37, P<0.001)$, and LDL-C $(3.00 \pm 0.82$ versus $2.44 \pm 0.53, t=-9.11, P<0.001)$ were also significantly higher among the hypertensive subjects. The mean HDL$\mathrm{C}$ was however comparable in the two groups $(1.25 \pm 0.27$ versus $1.24 \pm 0.04, t=-0.25, P=0.8$ ).

Table 2 shows the prevalence of various lipid abnormalities (based on the NCEP ATP III criteria). Among the hypertensive subjects; $131(52.4 \%)$ had at least one abnormal lipid parameter while $56(22.4 \%)$ of the controls had at least one lipid abnormality. Elevated TC was the most frequently occurring abnormality among the hypertensive subjects, $n=89$ (35.6\%), followed by elevated LDL-C, $n=71(28.4 \%)$. These abnormalities however often occurred together with other lipid abnormalities rather than in isolation. Participants with isolated low HDL-C (hypertensives, $n=54(21.6 \%)$; controls, $n=40(16.0 \%))$ represented $41.2 \%$ and $71.6 \%$ of all hypertensives subjects and controls with dyslipidemia respectively. Isolated low HDL-C was therefore the most frequent individual lipid abnormality among both the hypertensive subjects and controls. Table 3 shows the Spearman's correlation coefficient between the serum lipid indices and various clinical and biochemical 
TABLE 1: Shows the demographic, clinical, and biochemical profile of the subjects and controls.

\begin{tabular}{|c|c|c|c|c|}
\hline Variable & $\begin{array}{c}\text { Subjects } \\
\text { Mean + SD }\end{array}$ & $\begin{array}{c}\text { Controls } \\
\text { Mean + SD }\end{array}$ & $t$ & $P$ value \\
\hline Age (years) & $58.5 \pm 12.4$ & $57.8 \pm 12.5$ & -0.6 & 0.6 \\
\hline $\mathrm{SBP}(\mathrm{mm} \mathrm{Hg})$ & $163.3 \pm 18.9$ & $115.5 \pm 10.1$ & -38.9 & $<0.001$ \\
\hline DBP (mm Hg) & $99.1 \pm 11.7$ & $70.9 \pm 9.1$ & -30 & $<0.001$ \\
\hline BMI $\left(\mathrm{kg} / \mathrm{m}^{2}\right)$ & $28.8 \pm 5.8$ & $26.7 \pm 4.4$ & -4.5 & $<0.001$ \\
\hline $\mathrm{WC}(\mathrm{cm})$ & $96.4 \pm 13.4$ & $90.8 \pm 10.8$ & -5.1 & $<0.001$ \\
\hline WHR & $0.97 \pm 0.07$ & $0.94 \pm 0.06$ & -4.9 & $<0.001$ \\
\hline $\mathrm{FBS}(\mathrm{mmol} / \mathrm{L})$ & $5.0 \pm 1.2$ & $4.6 \pm 0.8$ & -5.3 & $<0.001$ \\
\hline TG & $1.23 \pm 0.32$ & $1.10 \pm 0.24$ & -5.4 & $<0.001$ \\
\hline HDL-C & $1.25 \pm 0.27$ & $1.24 \pm 0.57$ & -0.3 & $=0.8$ \\
\hline LDL-C & $3.00 \pm 0.82$ & $2.44 \pm 0.53$ & -9.1 & $<0.001$ \\
\hline TC & $4.83 \pm 0.95$ & $4.15 \pm 0.57$ & -9.7 & $<0.001$ \\
\hline
\end{tabular}

SBP: systolic blood pressure; DBP: diastolic blood pressure; BMI: body mass index; WC: waist hip ratio; FGS: fasting blood sugar; TG: triglycerides; HDL-C: high density lipoprotein cholesterol; LDL-C: low density lipoprotein cholesterol; TC: total cholesterol.

TABle 2: Prevalence of various serum lipid abnormalities among the study participants.

\begin{tabular}{lcc}
\hline Lipid abnormality & $\begin{array}{c}\text { hypertensives } \\
n(\%)\end{array}$ & $\begin{array}{c}\text { controls } \\
n(\%)\end{array}$ \\
\hline Elevated TC $(\geq 5.2 \mathrm{mmol} / \mathrm{L})$ & $89(35.6)$ & $16(6.4)$ \\
Elevated LDL-C $(\geq 3.4 \mathrm{mmol} / \mathrm{L})$ & $71(28.4)$ & $15(6.0)$ \\
Elevated TG $(\geq 1.7 \mathrm{mmol} / \mathrm{L})$ & $16(6.4)$ & $2(0.8)$ \\
Low HDL-C $(<1.04 \mathrm{mmol} / \mathrm{L})$ & $54(21.6)$ & $40(16.0)$ \\
No lipid abnormality & $119(47.6)$ & $194(77.6)$ \\
One lipid abnormality & $54(21.6)$ & $41(16.4)$ \\
$\geq 2$ lipid abnormality & $77(30.8)$ & $15(6.0)$ \\
At least one abnormality & $131(52.4)$ & $56(22.4)$ \\
\hline
\end{tabular}

TG: triglycerides; HDL-C: high density lipoprotein cholesterol; LDL-C: low density lipoprotein cholesterol; TC: total cholesterol.

parameters. Among the hypertensive subjects, there was a statistically significant positive correlation between BMI and TC $(r=0.176, P=0.005)$; BMI and LDL-C $(r=0.176, P=$ $0.005)$; BMI and TG $(r=0.288, P<0.001)$; WC and TG $(r=$ $0.293, P<0.001)$; FBS and TC $(r=0.168, P=0.008)$; FBS and LDL-C $(r=0.172, P=0.006)$; FBS and TG $(r=0.136$, $P=0.03)$. On the other hand, HDL-C showed a statistically significant inverse correlation with WHR $(r=-0.241, P<$ 0.001 ) among the hypertensive subjects. Among the control, there was no statistically significant correlation between the lipid indices and any of the above clinical (SBP, DBP, BMI, WC, WHR) or biochemical (FBS) parameters. Table 4 shows the multiple regression analysis with total cholesterol, HDLC, LDL-C, and triglycerides as dependent variables and BP, age, BMI, sex, and FBG as independent variables.

\section{Discussion}

In this study, serum TC, TG, and LDL-L concentrations are significantly higher in hypertensive patients than in normotensive subjects. This is consistent with earlier observations in parts of the world and in other parts of Nigeria
[17, 20-25]. This is unlike the findings of Akintunde [26], Lepira et al. [27] and Kesteloot et al. [28] who reported that the TC, TG, and LDL-C of newly diagnosed hypertensive patients did not differ significantly from that of control subjects, though the newly diagnosed hypertensive tended to have a higher level of LDL-C, TG, TC.

In our study, serum TC concentrations are significantly higher in hypertensive patients than in normotensive subjects. This is consistent with earlier observations in parts of the world and in other parts of Nigeria [17, 20-24, 29]. High levels of serum cholesterol are known to increase the risk of developing macrovascular complications such as coronary heart disease (CHD) and stroke [30]. Many epidemiological studies indicate a progressive increase in CHD risk as the serum TC exceeds $5.0 \mathrm{mmol} / \mathrm{L} \mathrm{[31]} \mathrm{which}$ prompted Lewis [32] to suggest that levels of serum TC in the range $5.0-6.5 \mathrm{mmol} / \mathrm{L}$ to be considered undesirable. It is to be noted that there was positive and significant correlation between serum TC and both systolic and diastolic BP in both hypertensive patients and normotensive controls. Similarly, there were statistically significant correlations between serum TC and BMI among both hypertensive and normotensive groups. The hypertensive patients had significantly higher BMI and WHR than the controls. This observation may be due to common risk factors for hypertension, obesity and dyslipidaemia as obesity, is known to play a central role in the causation and sustenance of insulin resistance [20], though our study was a cross-sectional study. The exact pathogenetic mechanisms underlying the CVD risk mediated by dyslipidemia are not fully elucidated, but high levels of serum cholesterol are known to increase the risk of developing macrovascular complications such as coronary heart disease (CHD) and stroke [30]. Epidemiological studies indicate a progressive increase in CHD risk as the serum TC exceeds $5.0 \mathrm{mmol} / \mathrm{L}$ [31]. It is thus generally recognized and recommended that treatment of hypertension should, in addition to lowering blood pressure, target correction of dyslipidemia (as well as other CVD risk factors) if present, to reduce overall CVD risk and increase the cost-effectiveness of therapy. 
TABLE 3: Showing Spearman's correlations between lipid profile and clinical parameters.

\begin{tabular}{lcccccccc}
\hline & \multicolumn{2}{c}{ TC } & \multicolumn{2}{c}{ LDL-C } & \multicolumn{2}{c}{ HDL-C } & \multicolumn{2}{c}{ TG } \\
& Subjects & Controls & Subjects & Controls & Subjects & Controls & Subjects & Controls \\
\hline SBP & -0.032 & -0.047 & -0.013 & -0.041 & -0.034 & 0.101 & 0.003 \\
DBP & -0.054 & -0.041 & -0.042 & -0.007 & -.066 & 0.055 & -0.015 \\
BMI & $0.176^{* *}$ & 0.061 & $0.176^{* *}$ & 0.067 & -0.001 & 0.004 & $0.288^{* *}$ & 0.026 \\
WC & 0.102 & 0.081 & 0.097 & 0.075 & $-0.241^{* *}$ & -0.041 & $0.293^{* *}$ & 0.042 \\
WHR & -0.101 & 0.013 & -0.087 & 0.052 & -0.063 & -0.117 & 0.120 & -0.038 \\
FBS & $0.168^{* *}$ & 0.54 & $0.172^{* *}$ & 0.009 & -0.115 & 0.029 & $0.136^{*}$ & 0.06 \\
\hline
\end{tabular}

*Correlation significant at $P=0.05$; ${ }^{*}$ Correlation significant at $P=0.001$; TG: triglycerides; HDL-C: high density lipoprotein cholesterol; LDL-C: low density lipoprotein cholesterol; TC: total cholesterol.

TABLE 4: Shows the multiple regression analysis with total cholesterol, HDL-C, LDL-C, and triglycerides as dependent variables and BP, age, BMI, sex, and FBG as independent variables.

\begin{tabular}{|c|c|c|c|c|c|}
\hline & \multicolumn{2}{|c|}{ Unstandardized coeff } & \multirow[t]{2}{*}{ Standardized coeff } & \multirow[b]{2}{*}{$t$} & \multirow{2}{*}{ sig } \\
\hline & $B$ & Std error & & & \\
\hline \multicolumn{6}{|c|}{ Triglycerides: F5,494 $=7.741$ Adjusted $R=.063 P<0.0001$} \\
\hline Constant & .518 & .112 & & 4.630 & .000 \\
\hline SBP & .001 & .000 & .148 & 3.257 & $.001^{* *}$ \\
\hline BMI & .008 & .002 & .150 & 3.337 & $.001^{* *}$ \\
\hline Age & .002 & .001 & .088 & 2.012 & $.045^{*}$ \\
\hline FBG & .020 & .013 & .070 & 1.572 & .117 \\
\hline Sex & .009 & .025 & .015 & .342 & .732 \\
\hline \multicolumn{6}{|c|}{ LDL-C: F5,494 = 23.245 Adjusted $R=.182 P<0.0001$} \\
\hline Constant & .702 & .270 & & 2.602 & .010 \\
\hline SBP & .006 & .001 & -.248 & 5.830 & $.000^{* *}$ \\
\hline BMI & .011 & .006 & .080 & 1.908 & .057 \\
\hline Age & .006 & .002 & .095 & 2.338 & $.020^{*}$ \\
\hline FBG & .137 & .031 & .185 & 4.432 & $.000^{* *}$ \\
\hline Sex & -.285 & .061 & -.191 & 4.644 & $.000^{* *}$ \\
\hline \multicolumn{6}{|c|}{ HDL-C: F5,494 = 2.286 Adjusted $R=.013 P<0.0001$} \\
\hline Constant & 1.339 & .176 & & 7.628 & .000 \\
\hline SBP & .000 & .001 & .030 & .642 & .521 \\
\hline BMI & -.004 & .004 & -.047 & -1.025 & .306 \\
\hline Age & .000 & .002 & .005 & .103 & .918 \\
\hline FBG & .003 & .020 & .007 & .150 & .881 \\
\hline Sex & .131 & .040 & -.148 & -3.285 & $.001^{* *}$ \\
\hline \multicolumn{6}{|c|}{ Total Cholesterol: F5,494 $=26.171$ Adjusted $R=.201$} \\
\hline Constant & 2.162 & .305 & & 7.081 & .000 \\
\hline SBP & .008 & .001 & .267 & 6.362 & $.000^{* *}$ \\
\hline BMI & .013 & .007 & .077 & 1.856 & .064 \\
\hline Age & .007 & .003 & .101 & 2.514 & $.012^{*}$ \\
\hline FBG & .147 & .035 & .174 & 4.211 & $.000^{* *}$ \\
\hline Sex & -.373 & .069 & .218 & -5.373 & $.000^{* *}$ \\
\hline
\end{tabular}

Isolated low HDL-C was the most common individual lipid abnormality among the study participants especially in the controls among whom it represented $71.4 \%$ of all forms of dyslipidaemia. Akintunde [26] had earlier reported a similar finding in Osogbo. Odenigbo et al. [33] reported a high rate of low HDL-C among apparently healthy professionals in Asaba, a town which is located in close proximity to Nnewi, our study location. The ATP III guidelines recognize isolated HDL-C as a distinct form of atherogenic dyslipidaemia but state that it is not common in the general population. Our data and those of Odenigbo et al. [33] however suggest that isolated low HDL-C may 
be a relatively common baseline lipid abnormality among the general population in this part of Nigeria and that the presence of hypertension only escalates it. HDL-C can result in endothelial damage and trigger an increase in BP. The exact mechanism by which a low HDL-C increases CVD risk has however not been fully elucidated, though experimental studies suggest a direct role for HDL-C in promoting cholesterol efflux (this is called reverse cholesterol transport) from foam cells in the atherosclerotic plaque depots in blood vessels to the liver for excretion. HDL$\mathrm{C}$ also exhibits potent anti-inflammatory and antioxidant effects that inhibit the atherogenic process $[34,35]$. It has additionally been shown that a low HDL-C level correlates with the presence of other atherogenic risk factor (some of which are emerging risk factors not considered separately during prevalence). According to Pavithran et al. [25] alteration in lipid metabolism including a decrease in HDL$C$ can result in endothelial damage and trigger an increase in blood pressure which may partially account for its strong predictive power for $\mathrm{CHD}$.

It has long been known that a low level of HDL cholesterol is a powerful predictor of increased cardiovascular risk [36-39]. Eapen et al. [40] showed that male and female patients with low HDL-C levels $(<35 \mathrm{mg} / \mathrm{dL})$ and with normal total cholesterol levels have more cardiovascular events (such as heart attacks and unstable chest pain) as compared to their adult counterparts with high HDL-C levels. There is strong epidemiological evidence that low HDL-C is an independent risk factor for CVD [36, 38] with strong suggestions that interventions to increase HDLcholesterol will yield clinically significant outcome benefits. The Multiple Risk Factor Intervention Trial [41] showed that each decrease in HDL-cholesterol of $1 \mathrm{mg} / \mathrm{dL}(0.03 \mathrm{mmol} / \mathrm{L})$ was associated with an increase in the risk of coronary heart disease of $2 \%$ in men and $3 \%$ in women. It has been shown that a $1 \%$ reduction in HDL-C is associated with a 2-3\% increase in CHD risk. Mounting clinical and experimental evidence show that HDL-Cs exert multiple antiatherogenic and antithrombotic effects that together are consistent with a marked reduction in the risk of a morbid cardiovascular event, supporting an anti-atherogenic role for HDL-cholesterol [41, 42]. In recognition of its status as a CVD risk factor, ATP III recommends that a low HDL-C ( $\leq 40 \mathrm{mg} / \mathrm{dL}$ which is equivalent to $\leq 1.04 \mathrm{mmol} / \mathrm{L}$ for both men and women) should be a secondary target of therapy aimed at lipid lowering to reduce CVD risk. However several studies have not borne this out $[43,44]$.

Hypertension and dyslipidaemia are well known to frequently coexist. The coexistence of hypertension and dyslipidaemia has multidimensional clinical implications. First, CVD risk is synergistically enhanced and for this reason, both conditions should be treated aggressively [2]. This association has been linked to background central obesity and consequent insulin resistance which are underlying factors that play major roles in the pathogenesis of both hypertension and dyslipidaemia. The results of a 7 year follow-up study on Finnish men suggested that dyslipidemia characteristic of the metabolic syndrome predicted the development of hypertension [45]. Halperin et al. [3] had also shown that dyslipidemia in apparently healthy individuals leads to hypertension. Hausmann et al. [46] in their intravascular ultrasound studies demonstrated that patients with low HDL cholesterol and high TG levels have more extensive coronary atheromas than those with an isolated elevation of LDL cholesterol.

Finally, despite the relatively low incidence and burden of coronary heart disease risk factors in black Africans, highrisk groups such as hypertensives may need to be more fully evaluated for lipid abnormalities and therapy initiated early for those found with lipid abnormalities.

\section{Limitations of the Study}

Our study has several limitations. One study limitation is the fact that our study did not collect data from all parts of the country and at best it could only be speculated whether observed relationship is similar all over the country. Secondly being a cross-sectional study by design it cannot observe prospectively and thus cannot associate causal relationships between the factors under study. Finally it is a hospital based study and may not truly represent the population at large as the risk profile of those who did not come to hospital may differ from those who did.

\section{Conclusion}

This study has shown that lipid abnormalities are highly prevalent among newly diagnosed hypertensive patients in South East Nigeria. Efforts should therefore be intensified to fully evaluate Nigerians with hypertension from a lipid and lipoprotein standpoint, and any abnormalities detected are to be taken into consideration during therapy of this group of high-risk patients.

\section{References}

[1] W. B. Kannel, W. P. Castelli, T. Gordon, and P. M. McNamara, "Serum cholesterol, lipoproteins, and the risk of coronary heart disease. The Framingham study," Annals of Internal Medicine, vol. 74, no. 1, pp. 1-12, 1971.

[2] R. R. Williams, S. C. Hunt, P. N. Hopkins et al., "Familial dyslipidemic hypertension. Evidence from 58 Utah families for a syndrome present in approximately $12 \%$ of patients with essential hypertension," Journal of the American Medical Association, vol. 259, no. 24, pp. 3579-3586, 1988.

[3] R. O. Halperin, H. D. Sesso, J. Ma, J. E. Buring, M. J. Stampfer, and J. M. Gaziano, "Dyslipidemia and the risk of incident hypertension in men," Hypertension, vol. 47, no. 1, pp. 45-50, 2006.

[4] C. Borghi, "Interactions between hypercholesterolemia and hypertension: implications for therapy," Current Opinion in Nephrology and Hypertension, vol. 11, no. 5, pp. 489-496, 2002.

[5] J. D. Neaton and D. Wentworth, "Serum cholesterol, blood pressure, cigarette smoking, and death from coronary heart disease: overall findings and differences by age for 316099 white men," Archives of Internal Medicine, vol. 152, no. 1, pp. 56-64, 1992. 
[6] J. C. Edozien, "Establishment of a biochemical norm for the evaluation of nutrition status in West Africa," Journal of West African Science Association, vol. 10, pp. 3-21, 1965.

[7] A. C. Onitiri, M. Sander, and A. E. Boyo, "Serum lipids and lipoproteins in healthy Africans," Clinica Chimica Acta, vol. 81, no. 1, pp. 57-61, 1977.

[8] J. T. Knuiman and C. E. West, "HDL cholesterol in men from thirteen countries," The Lancet, vol. 2, no. 8242, pp. 367-368, 1981.

[9] G. O. Taylor and E. O. Agbedana, "A comparative study of plasma high-density lipoprotein cholesterol in two groups of Nigerians of different socio-economic status," African Journal of Medicine and Medical Sciences, vol. 12, no. 1, pp. 23-28, 1983.

[10] J. Olusakin, A. D. T. Goji, I. Ezekiel, S. S. Dare, S. B. Mesole, and Y. G. Mohammed, "Evaluation of some risk factors for atherosclerosis in the Circle of Willis observed at autopsy in UCH, Ibadan Nigeria," Asian Journal of Medical Sciences, vol. 3, no. 5, pp. 186-191, 2011.

[11] V. Aboyans, P. Lacroix, and M. H. Criqui, "Large and small vessels atherosclerosis: similarities and differences," Progress in Cardiovascular Diseases, vol. 50, no. 2, pp. 112-125, 2007.

[12] World Health Organization, Global Health Risks: Morality and Burden of Disease Attributable To Selected Major Risks, World Health Organization, Geneva, Switzerland, 2009.

[13] T. A. Gaziano, A. Bitton, S. Anand, and M. C. Weinstein, "The global cost of nonoptimal blood pressure," Journal of Hypertension, vol. 27, no. 7, pp. 1472-1477, 2009.

[14] O. O. Akinkugbe, Ed., "Non-communicable diseases in Nigeria, Series 4," Final report of National Survey. Federal Ministry of Health and Human Services.

[15] W. O. Ehrun, G. Olayiwola, E. O. Agbani, and N. S. Omotoso, "Prevalence of hypertension in a university community South West Nigeria," African Journal of Biomedical Research, vol. 8, pp. 15-19, 2005.

[16] G. I. Ahaneku, C. U. Osuji, B. C. Anisiuba, V. O. Ikeh, O. C. Oguejiofor, and J. E. Ahaneku, "Evaluation of blood pressure and indices of obesity in a typical rural community in eastern Nigeria," Annals of African Medicine, vol. 10, no. 2, pp. 120126, 2011.

[17] J. M. Harvey and D. G. Beevers, "Biochemical investigation of hypertension," Annals of Clinical Biochemistry, vol. 27, no. 4, pp. 287-296, 1990.

[18] Third Report of the National Cholesterol Education Program (NCEP), "Expert panel on detection, evaluation, and treatment of high blood cholesterol in adults (Adult Treatment Panel III) final report," Circulation, vol. 106, pp. 3143-3421, 2002.

[19] A. V. Chobanian, G. L. Bakris, H. R. Black et al., "The seventh report of the Joint National Committee on Prevention, Detection, Evaluation, and Treatment of High Blood Pressure: the JNC 7 report," Journal of the American Medical Association, vol. 289, no. 19, pp. 2560-2572, 2003.

[20] R. Pelkonen, E. A. Nikkila, and S. Koskinen, "Association of serum lipids and obesity with cardiovascular mortality," British Medical Journal, vol. 2, no. 6096, pp. 1185-1187, 1977.

[21] E. K. Oghagbon and A. B. Okesina, "Pattern of some risk factors for cardiovascular disease in untreated Nigerian hypertensive patients," West African Journal of Medicine, vol. 25, no. 3, pp. 190-194, 2006.

[22] V. A. Ukoh and I. A. O. Oforofuo, "Plasma lipid profiles in Nigerians with normal blood pressure, hypertension and other acquired cardiac conditions," East African Medical Journal, vol. 84, no. 6, pp. 264-270, 2007.

[23] M. R. Akpa, D. I. Agomouh, and D. D. Alasia, "Lipid profile of healthy adult Nigerians in Port Harcourt, Nigeria," Nigerian Journal of Medicine, vol. 15, no. 2, pp. 137-140, 2006.

[24] O. O. Oyelola, A. A. Ajayi, R. O. Babalola, and E. A. Stein, "Plasma lipids, lipoproteins, and apolipoproteins in Nigerian diabetes mellitus, essential hypertension, and hypertensivediabetic patients," Journal of the National Medical Association, vol. 87, no. 2, pp. 113-118, 1995.

[25] P. Pavithran, H. Nandeesha, Madanmohan et al., "Dyslipidemia antedates occurrence of clinical hypertension in non-diabetic, non-obese male subjetcs," Indian Journal of Physiology and Pharmacology, vol. 51, no. 1, pp. 96-98, 2007.

[26] A. A. Akintunde, "Epidemiology of conventional cardiovascular risk factors among hypertensive subjects with normal and impaired fasting glucose," South African Medical Journal, vol. 100, no. 9, pp. 594-597, 2010.

[27] F. B. Lepira, J. R. M’Buyamba-Kabangu, K. P. Kayembe, and M. N. Nseka, "Correlates of serum lipids and lipoproteine in Congolese patients with arterial hypertension," Cardiovascular Journal of South Africa, vol. 16, no. 5, pp. 249-255, 2005.

[28] H. Kesteloot, C. S. Lee, and H. M. Park, "A comparative study of serum lipids between Belgium and Korea," Circulation, vol. 65, no. 4, pp. 795-799, 1982.

[29] S. A. Akuyam, U. B. Aghogho, I. S. Aliyu, and A. G. Bakari, "Serum total cholesterol in hypertensive Northern Nigerians," International Journal of Medicine and Medical Sciences, vol. 1, pp. 73-78, 2009.

[30] J. F. Albucher, J. Ferrieres, J. B. Ruidavets, B. GuiraudChaumeil, B. P. Perret, and F. Chollet, "Serum lipids in young patients with ischaemic stroke: a case-control study," Journal of Neurology Neurosurgery and Psychiatry, vol. 69, no. 1, pp. 29-33, 2000.

[31] H. C. McGill Jr, "Introduction to the geographic pathology of atherosclerosis," Laboratory Investigation, vol. 18, no. 5, pp. 465-467, 1968.

[32] B. Lewis, "The appropriate use of diagnostic services: (viii) the investigation of hyperlipidaemia: why, how and for whom?" Health trends, vol. 18, no. 1, pp. 1-4, 1986.

[33] C. U. Odenigbo, O. C. Oguejiofor, U. M. Odenigbo, C. C. Ibeh, C. N. Ajaero, and M. A. C. Odike, "Prevalence of dyslipidaemia in apparently healthy professionals in asaba, South South Nigeria," Nigerian Journal of Clinical Practice, vol. 11, no. 4, pp. 330-335, 2008.

[34] P. J. Barter, S. Nicholls, K. A. Rye, G. M. Anantharamaiah, M. Navab, and A. M. Fogelman, "Antiinflammatory properties of HDL,” Circulation Research, vol. 95, no. 8, pp. 764-772, 2004.

[35] M. I. Mackness, P. N. Durrington, and B. Mackness, "How high-density lipoprotein protects against the effects of lipid peroxidation," Current Opinion in Lipidology, vol. 11, no. 4, pp. 383-388, 2000.

[36] G. Assmann, H. Schulte, A. Von Eckardstein, and Y. Huang, "High-density lipoprotein cholesterol as a predictor of coronary heart disease risk. The PROCAM experience and pathophysiological implications for reverse cholesterol transport," Atherosclerosis, vol. 124, pp. S11-S20, 1996.

[37] J. D. Curb, R. D. Abbott, B. L. Rodriguez et al., "A prospective study of HDL-C and cholesteryl ester transfer protein gene mutations and the risk of coronary heart disease in the elderly," Journal of Lipid Research, vol. 45, no. 5, pp. 948-953, 2004.

[38] A. R. Sharrett, C. M. Ballantyne, S. A. Coady et al., "Coronary heart disease prediction from lipoprotein cholesterol levels, 
triglycerides, lipoprotein(a), apolipoproteins A-I and B, and HDL density subfractions: the Atherosclerosis Risk in Communities (ARIC) Study," Circulation, vol. 104, no. 10, pp. 1108-1113, 2001.

[39] T. Gordon, W. P. Castelli, and M. C. Hjortland, "High density lipoprotein as a protective factor against coronary heart disease. The Framingham study," American Journal of Medicine, vol. 62, no. 5, pp. 707-714, 1977.

[40] D. J. Eapen, G. L. Kalra, L. Rifai, C. A. Eapen, N. Merchant, and B. V. Khan, "Raising HDL cholesterol in women," International Journal of Women's Health, vol. 1, no. 1, pp. 181-191, 2009.

[41] D. J. Gordon, J. L. Probstfield, R. J. Garrison et al., "Highdensity lipoprotein cholesterol and cardiovascular disease. Four prospective American studies," Circulation, vol. 79, no. 1, pp. 8-15, 1989.

[42] P. Barter, "The role of HDL-cholesterol in preventing atherosclerotic disease," European Heart Journal, Supplement, vol. 7, pp. F4-F8, 2005.

[43] The Accord Study Group, "Effects of combination lipid therapy in type 2 diabetes mellitus," New England Journal of Medicine, vol. 362, no. 17, pp. 1563-1574, 2010.

[44] The AIM-HIGH Investigators, "Niacin in patients with low high density lipoprotein cholesterol levels receiving intensive statin therapy," New England Journal of Medicine, vol. 365, pp. 2255-2267, 2011.

[45] D. E. Laaksonen, L. Niskanen, K. Nyyssönen, T. A. Lakka, J. A. Laukkanen, and J. T. Salonen, "Dyslipidaemia as a predictor of hypertension in middle-aged men," European Heart Journal, vol. 29, no. 20, pp. 2561-2568, 2008.

[46] D. Hausmann, J. A. Johnson, K. Sudhir et al., "Angiographically silent atherosclerosis detected by intravascular ultrasound in patients with familial hypercholesterolemia and familial combined hyperlipidemia: correlation with high density lipoproteins," Journal of the American College of Cardiology, vol. 27, no. 7, pp. 1562-1570, 1996. 


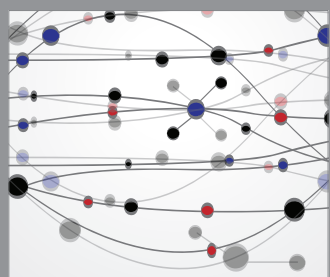

The Scientific World Journal
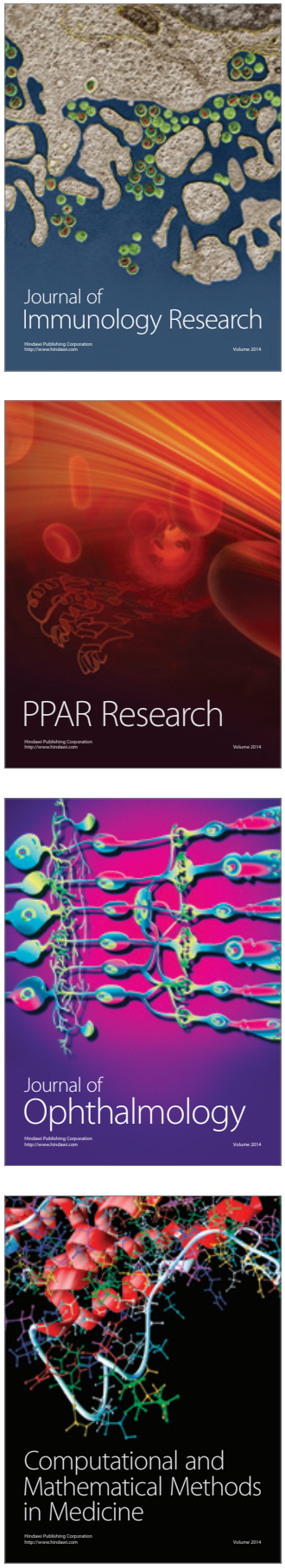

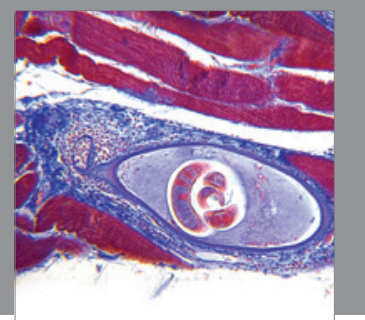

Gastroenterology

Research and Practice
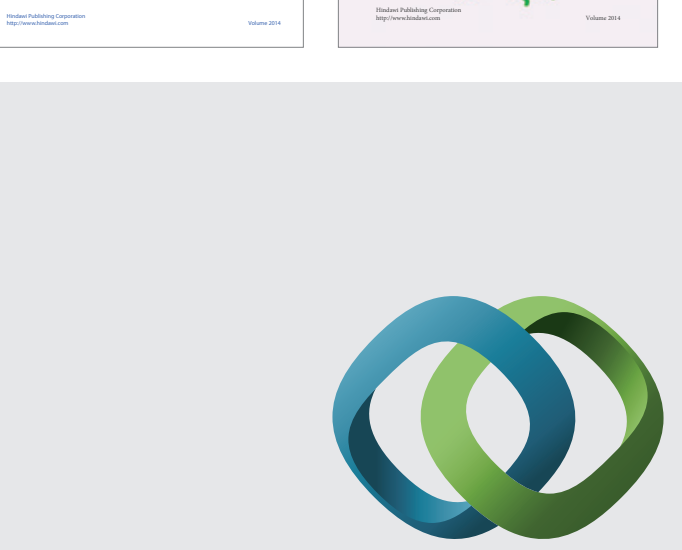

\section{Hindawi}

Submit your manuscripts at

http://www.hindawi.com
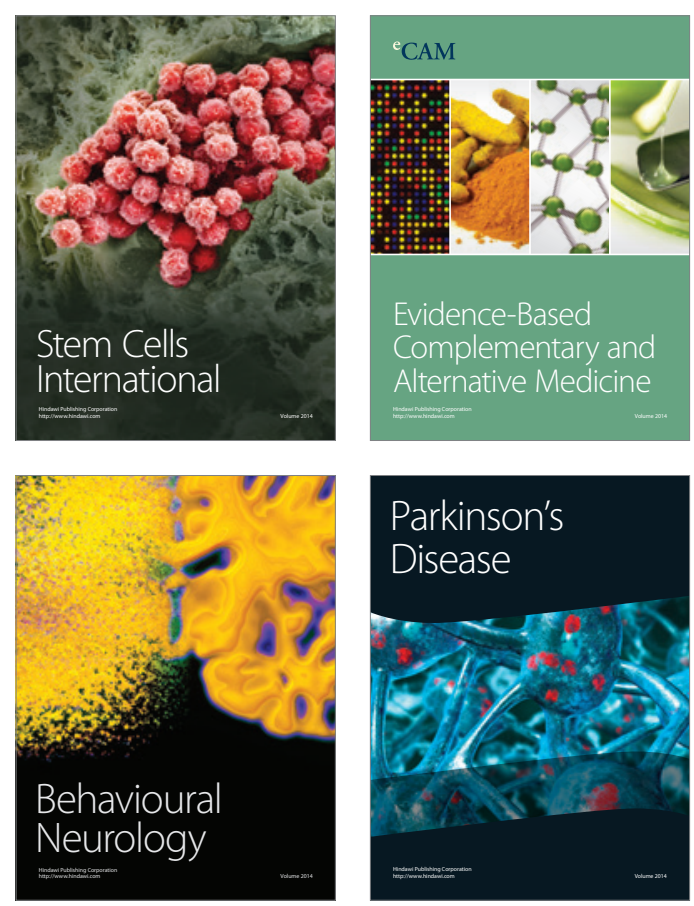

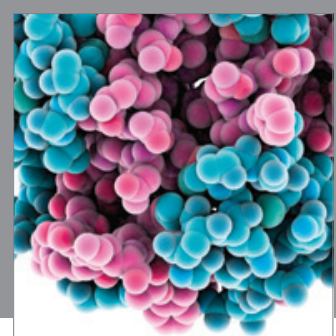

Journal of
Diabetes Research

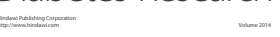

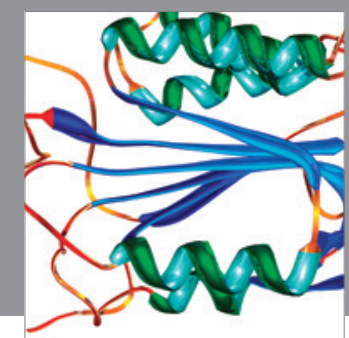

Disease Markers
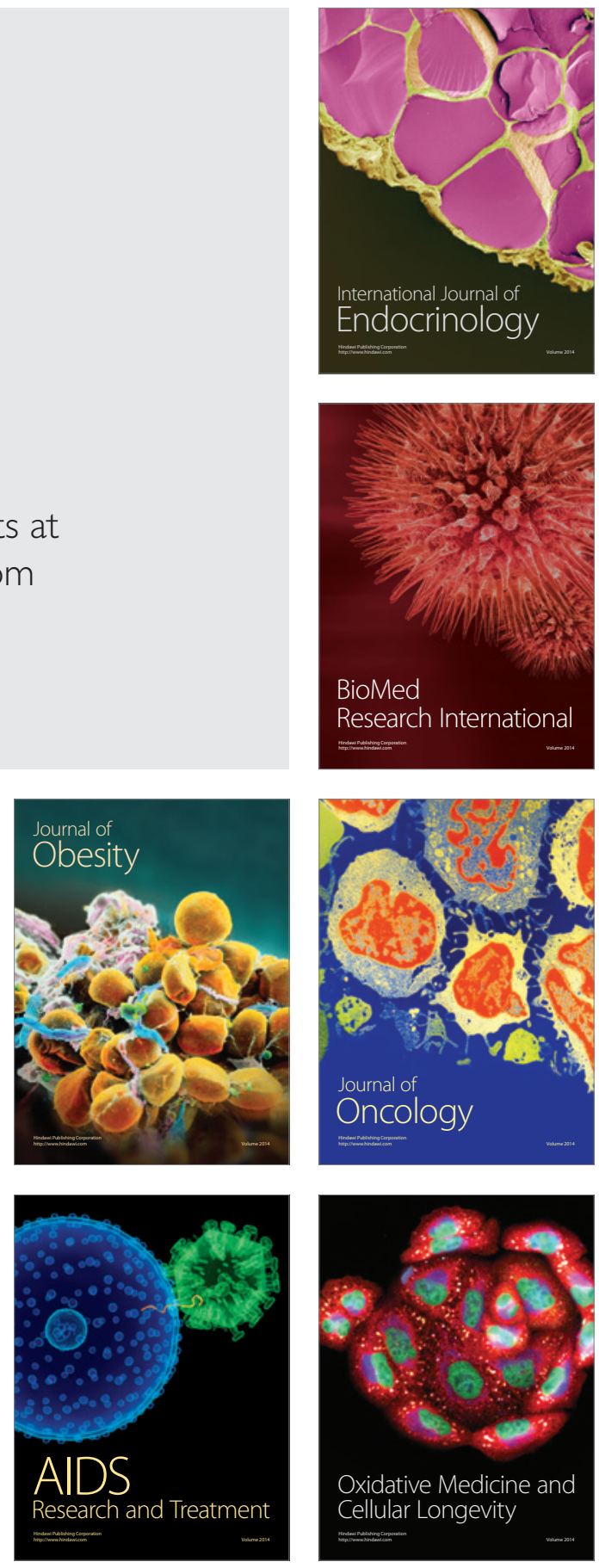